THURSDAY, APRIL 13, 1876

\section{A RESEARCH FUND FOR THE CHEMICAL SOCIETY}

$A \mathrm{~N}$ offer has lately been made to the Chemical Society, A which has for its object the establishing of a fund to be applied in aiding the development of scientific chemistry. The offer comes from Dr. Longstaff, who proposes giving the society the sum of $1,000 l$., on condition that at least an equal amount be raised and invested together with his gift, in approved security. To make this offer known to the Fellows of the Chemical Society, the following circular has been sent to them, and already the major part of the required $\mathrm{I}, 000 \mathrm{l}$. has, in donations varying from $x l$. to 100 ., been raised.

Chemical Society,

Burlington House, Piccadilly, W., March, 1876

Dear Sir,

$\mathrm{I}$ am instructed by the President and Council of the Chemical Society, to request your consideration of a matter, which they hope will elicit your interest and active co-operation.

The ac vancement of Chemical Science, which coustitutes the special object of the Chemical Society, may be promoted chiefly in two ways :-

I. By facilitating the early acquirement by students of Chemistry of a knowledge of the results of chemical research carried on in this and other countries.

2. By affording direct assistance to workers in chemical science, with a view to encourage and facilitate their labours in experimental research.

The Chemical Society has sought from the time of its foundation to aid in the first of these objects by the publication cf original papers communicated to the Society; and, during the last five years, a special guarantee fund and liberal aid from the Rritish Association for the Advancement of Science have enabled the Society to establish, on a firm footing, the publica tion of monthly abstracts of original papers published in this country and abroad, on chemistry and allied branches of science.

The Chemical Society has also recently endeavoured, as far as its funds would permit, to afford assistance to chemists undertaking original investigations, by the extension of its library, and occasionally by grants of small sums of money, when pecuniary aid was applied for. The limited resources of the society have, however, restricted the number and amount of these grants within very narrow limits. In $1872, \mathrm{Mr}$. T. Hyde Hills placed at the disposal of the Chemical Society the sum of $\mathrm{IO} l$ as the nucleus of a fund for promoting original research and offered under certain conditions, made with the object of securing the co-operation of others, to contribute a like sum annually. This attempt of Mr. Hills to form a research fund was not, at the time, seconded. The Council have, however, recently received from Dr. G. D. Longstaff, one of the original members, the generous offer to place at the disposal of the society, the sum of one thousand pounds $(1,000)$. ) towards establishing a permanent fund for promoting the advancement of Chemical Science, on the condition that not less than an equal amount be subscribed for the same purpose.

As the President and Council feel that such a fund would add much to the usefulness of their Society, and enable them to encourage still further the prosecution of Chemical Science, they are most desirous to secure to the Society the benefit of this munificent offer of Dr. Longstaff; and have therefore instructed me to ask your co-operation towards the attainment of this object. I remain, Yours obediently,

William J. Russeli, Treasurer.

Considering the use to be made of this fund, and the very large number of persons interested either in the scientific development of chemistry, or else in its many lucrative applications, it is not unreasonable to expect that a sum far larger than this $2,000 \%$. will be raised.

The feeling among those most interested and most active in raising this fund, is that there should be, in the

VoL. XIII, -No. 337 first place, a permanent fund, the dispensers of which should have large discretionary power as to how the income is to be spent, so long as it be strictly used for the advancement of scientific chemistry, and secondly, that this fund should be aided by annual subscriptions. It is hoped that the invested capital may from time to time be largely increased by gifts ; possibly as the real character and object of such a fund as this becomes better understood and more widely known, it may receive legacies and bequests such as now are devoted to charitable or religious purposes.

The direct income arising from the money which is to be invested in accordance with Dr. Longstaff's conditions cannot amount to any large sum; it is therefore hoped, and not without reason, that many will aid the fund by annual subscription, and while some may probably limit their subscriptions to a definite number of years, others may be willing to subscribe as long as they are assured that good and useful work is being done with the money thus raised.

A fund of this compound character has certain advantages; the invested capital gives permanency and keeps alive the interest in it, the subscriptions help most materially towards forming an income which will more nearly approach the requirements of the case, and there are many who would rather that what they give should be used for immediate requirements than that it should be funded for the benefit of unknown and possibly never-to-exist requirements in time to come.

One point has been urged against such a fund as this ; it is that we should look rather to the State to aid research than to private generosity, and that every private fund of this kind tends to relieve the Government of some of its obligations, whereas all scientific bodies ought rather to increase such obligations, not lessen them. On the other hand the State aid, if it is to be really efficient, must be such that it will at least to some extent open out a career for those willing and able to devote themselves successfully to original investigations; while from this fund no more could be expected than that it should afford a means by which some of the best known chemists of the day, as represented by the governing body of the Chemical Society, should have within their power the means of aiding particular investigations, publishing possibly important scientific tables or other data, and making important acquisitions of books or even instruments if such be specially required by the fellows of their Society in the prosecution of scientific investigation. Undoubtedly it is beyond all question that the sphere of usefulness of the Chemical Society will be much extended by the establishment of this research fund.

W. J. RUSSELL

\section{TAIT'S "RECENT ADVANCES IN PHYSICAL SCIENCE"}

Recent Advances in Physical Science. By P. G. Tait, M.A., formerly Fellow of St. Peter's College, Cambridge, Professor of Natural Philosophy in the University of Edinburgh. (London: Macmillan and Co., 1876.)

THESE lectures, we are told in the Preface, were 1 given in the Spring of 1874 , at the desire of a number of the friends of the author-mainly professional 